\title{
Decision Mathematics as Preparation for Undergraduate Computer Science
}

\author{
Ellie Darlington \\ Assessment Research and Development Division, Cambridge Assessment, Cambridge, CB2 1GG, UK \\ Email: darlington.e@cambridgeassessment.org.uk \\ Jessica Bowyer \\ University of Exeter Graduate School of Education, Exeter, EX1 2LU, UK
}

\begin{abstract}
In England and Wales, students commonly take what are called Advanced ' $A$ ' level examinations in their final two years of secondary school. Good passes in these examinations are required to be accepted onto university degree courses. 123 Computer Science students from 24 different UK universities participated in an online survey about their perceptions and experiences of A-level Mathematics and A-level Further Mathematics as preparation for the mathematical component of their degree. The majority reported that decision mathematics units that they had studied as part of either qualification had been good preparation for their degree. Additionally, those who had taken the Further Mathematics qualification were positive about their experience and its utility as preparation for undergraduate Computer Science. A-levels in Mathematics and Further Mathematics in England and Wales are currently undergoing significant reform. One of the major changes will see the removal of Decision Mathematics as an optional topic in A-level Mathematics, meaning that students who wish to study it must take Further Mathematics - a much less commonly studied subject. Consequently, this research might encourage admissions tutors to reconsider their admissions requirements for undergraduate Computer Science.
\end{abstract}

Index Terms-Mathematics, transition, assessment, decision mathematics, A-level.

\section{INTRODUCTION}

This section outlines the nature of secondary mathematics qualifications and undergraduate Computer Science education in England and Wales to contextualise the motivation for the research. This is necessary because the education system in the UK differs from other countries. For example, it is not compulsory for students to study mathematics after age 16 in England and Wales. Additionally, UK university applicants choose a subject to specialise or 'major' in before beginning their course. Once they begin their studies, generally it is not possible to change subject.

\section{A. Undergraduate Computer Science in the UK}

The proportion of undergraduate students studying Computer Science in the UK is low, and decreasing. In the 2002/03 academic year, they comprised $7.7 \%$ of all full-time undergraduates, but only $4.6 \%$ in $2014 / 15$ [1, 2]. Furthermore, attrition in undergraduate Computer Science in the UK in 2012/13 (of 17.8\%) was second only to mathematics that year [3]. In the United States,

Beaubouef and Mason [4] suggest that a high level of attrition in Computer Science is due to multiple factors including students' misconceptions about the nature of the subject, poor mathematical backgrounds, poor institutional pedagogy and course structure, and students' study habits.

However, the study of post-compulsory secondary Computer Science has increased substantially over recent years [5], suggesting that the subject might enjoy an increase in participation at undergraduate level in the coming years.

\section{B. Post-Compulsory Secondary Mathematics Qualifications in England and Wales}

In England and Wales, upper secondary students who aim to go to university generally specialise by taking Alevel examinations in three or four subjects around age 18 , having earned their General Certificate of Secondary Education (GSCE) qualifications in a wide range of subjects at age 16. A-level subjects may be chosen from a wide range, though students may be restricted in their choice by which subjects are taught at their school. There are no compulsory A-level subjects. Universities may require students to take particular subjects for admission to their degree courses in order to ensure new undergraduates have appropriate background knowledge and understanding.

A-levels are typically studied over the course of two years. It is possible to study the first year of the course only and be examined at the end of that, to earn an Advanced Subsidiary 'AS' level.

The study of mathematics post-16 is not compulsory in England and Wales (subject to achieving at least a grade $\mathrm{C}$ in $\mathrm{GCSE}^{1}$ Mathematics). Nonetheless, in 2016 the most

\footnotetext{
${ }^{1}$ Students typically study a range of GCSE subjects including science, English, languages and humanities. Students who pass GCSE Mathematics do not necessarily have to formally study any mathematics after this.
} 
popular A-level subject was Mathematics, studied by $11 \%$ of all A-level candidates [5]. A more advanced mathematical A-level is also available: A-level Further Mathematics. This must be studied in addition to A-level Mathematics because it builds on its content, whilst introducing new topics.

A-levels are currently modular, with A-level Mathematics comprising six equally-weighted units. Students study a mixture of pure and applied mathematics, with some choice in the applied content. Specifically, students currently take two applied mathematics units from three strands: Mechanics (5 sequential units available), Statistics (4 sequential units), and Decision Mathematics (2 sequential units). The two units may each be from the same strand, or students may take one unit from two different strands. Hence, there are six different routes through A-level Mathematics, resulting in students entering higher education with a variety of backgrounds in applied mathematics. Lecturers and admissions tutors cannot be certain how much mechanics, statistics or decision mathematics their students have studied unless they specifically ask applicants to give this information. It may not necessarily be the choice of the individual student as to which optional units they study, but rather a decision made by their school or teacher, perhaps influenced by student preference.

However, A-level qualifications are currently undergoing substantial reform, and students beginning to study A-level Mathematics in September 2017 will study an entirely different specification. All A-levels will become linearly assessed, and the content of A-level Mathematics and Further Mathematics will change. The government's Department for Education consulted with an expert panel of mathematics and mathematics education academics, and concluded that it was in the best interests of students and higher education if all Alevel Mathematics students studied exactly the same content [6]. This will reduce the variability in students' mathematical knowledge at the beginning of university, making it easier for universities to design first year courses, particularly when a pass in A-level Mathematics is a condition of entry.

From September 2017, students will study a core of pure mathematics content, alongside topics in statistics and mechanics. However, the option to study topics in decision mathematics as part of A-level Mathematics will no longer exist. This is in response to suggestions from universities that the content of the available decision mathematics units was irrelevant and that they were a 'soft' option [6].

\section{Mathematics Requirements for Undergraduate Courses in the UK}

A-level Mathematics is not always compulsory for admission to undergraduate Computer Science at British universities. Nonetheless, $42 \%$ of new undergraduates studying Computer Science in 2010 nonetheless took Alevel Mathematics [7].

However, the relatively high number of students with post-compulsory mathematics qualifications does not mean that new Computer Science undergraduates expect to be, or are excited by, studying mathematics once they begin their university studies $[8,9]$.

Gregory [10], a lecturer in Computer Science at the University of Central Lancashire, suggests that this negativity may stem from the notion that:

"...[s]tudents feel maths is not core to their learning experience, that they came to university to study computing not maths, that they haven't done maths for ages and have (happily) forgotten much of it, and anyway, how is it relevant to computing?"

One might suggest that a disconnect between students' expectations and experiences is fostered by Computer Science entry requirements, and students' experiences of studying Computer Science. The mathematical content of an A-level in a Computer Science-related subject, for example, could influence students' perceptions of the nature of the subject. Porkess [11] argues that there is room for more mathematical and statistical content to be included in A-level Computing, and recent changes have seen an increase in the mathematical content of Computer Science, Computing and ICT A-levels (see, for example, OCR $\left.[12]^{2}\right)$.

The mathematical focus in A-level Computing is reflected in universities' entry requirements. Universities do not necessarily ask that students have taken A-level Computing (or similar) to study for a Computer Science degree, which may be related to the low uptake of the subject: Computing and ICT comprised only $0.7 \%$ and $1.0 \%$ of all A-levels taken in 2016, respectively [5]. Instead, at many universities, A-level Mathematics is the only specific A-level subject required to study a Computer Science degree. However, lower ranking universities generally make no A-level Mathematics requirement, and merely ask that applicants have passed GCSE Mathematics.

A certain level of prior attainment in mathematics is required for undergraduate Computer Science courses all around the world [8], and this requirement is longstanding in the UK [13]. However, Gordon [9] observes that A-level Mathematics requirements for admission to Computer Science have decreased within recent decades, something he attributes to staff expertise, student recruitment and changes in the course content. Many lecturers of Computer Science believe that their students' mathematical background is not strong enough [13].

However, whilst it is widely acknowledged that mathematics is part of Computer Science, Baldwin, Walker and Henderson [14] claim that:

"many computer science and software engineering graduates function quite well as professionals without consciously applying mathematics to their work. This paradox leads mathematics to sit uncomfortably in undergraduate computer science curricula."

Furthermore, the government criteria for undergraduate degrees in Computing in the UK [15] do not make wide or specific references to any particular mathematics that

\footnotetext{
${ }^{2}$ OCR is one of three major awarding organisations (also known as examination boards) in the UK. Awarding organisations are responsible for setting and awarding qualifications such as GCSEs and A-levels.
} 
should be taught as part of the course. They state that aspects of computing overlap with other subject areas such as mathematics and that degrees in this area should develop students' problem solving and numeracy, but no further details are given.

\section{Impact of Mathematical Backgrounds on Performance}

Ofqual $^{3}[16]$ state that A-level Computer Science must include Boolean algebra, comparison and complexity and algorithms, and number representation and bases. The mathematics examined in A-level Computing has been found to be accessible, putting mathematics questions in the context of Computer Science [17]. The Nuffield Foundation [17] found that marks for answers to A-level Computing questions requiring mathematics amounted to $19-36 \%$ of the whole A-level. Hence, new undergraduate computer scientists who did not take A-level Mathematics, but instead studied A-level Computer Science/Computing/ICT, would likely have limited backgrounds in mathematics.

To supplement this, universities often develop introductory courses so as to deepen students' mathematical knowledge using interdisciplinary teaching (e.g. [18]). Additionally, support classes and diagnostic testing have been introduced in a number of Computer Science departments $[19,20]$ in order to provide for students who have not taken any post-compulsory mathematics.

Students who have stronger backgrounds in mathematics have been found to be more successful in the study of undergraduate Computer Science [10, 21, 22, 23]. The Computer Science education literature points towards decision mathematics as being the most useful preparation for undergraduate Computer Science [8, 24, $25,26]$.

Specifically, Pioro [27] found that backgrounds in decision mathematics and calculus had strong influences on students' performance in a Computing course at an American university. Graham, Knuth and Patashnik [28] describe the importance of continuous and discrete mathematics ('concrete' mathematics) in supporting the study of Computer Science. Topics covered include asymptotic methods, number theory, binomial coefficients, discrete probability and recurrences. Additionally, the University of Cambridge - the highestranking university for Computer Science in the UK [29] recommends that new students are able to answer the questions in a workbook they supply [30]. The topics covered in the workbook are algebra, functions and curve sketching, geometry, sequences and series, trigonometry, vectors, and calculus.

\section{E. Research Aims}

The research outlined in this article was conducted due to reforms targeting A-level Mathematics and Further Mathematics, which have changed their structure and

\footnotetext{
${ }^{3}$ Ofqual is the Office of Qualifications and Examinations Regulation, a non-ministerial government department which regulates qualifications and assessment in England.
}

content. We sought to investigate the views of current undergraduate computer scientists about their mathematical preparation for university by A-level Mathematics and/or Further Mathematics. We sought to answer the following research questions:

1. Which optional units in A-level Mathematics and/or Further Mathematics did undergraduate computer scientists find had been useful preparation for the mathematical component of their degree?

2. What motivated the Computer Science undergraduates who took Further Mathematics at school to take it, and what were their experiences of studying it?

3. Do those Computer Science students who took Alevel Mathematics and/or Further Mathematics believe the qualification was useful preparation for their degree?

4. Are there any areas in which A-level Mathematics and/or Further Mathematics could be improved to suit the needs of future prospective undergraduate computer scientists?

Whilst this article focuses on the views of undergraduate computer scientists, the data was collected as part of an overarching project [31] which sought the views of students of a variety of other science and social science degree subjects on their mathematical experiences, the results of which are reported elsewhere.

\section{METHODS}

In order to gather the views of as wide a range of students as possible, all universities in Great Britain which offer Computer Science-related degree courses were contacted via their websites. Computer Science departments were asked to disseminate details of an online questionnaire aimed at students who fulfilled two criteria:

1. They must have been in their second year of study or above, in order that they could reflect on their experiences so far.

2. They must have taken at least AS-level Mathematics since 2006 (when the qualification underwent its most recent restructuring).

The questionnaire surveyed students regarding:

- Mathematical backgrounds: Participants' mathematics qualifications and grades, and units studied as part of A-level Mathematics and/or Further Mathematics.

- Current studies: Their university and year of study.

- Perceptions of A-level Mathematics and Further Mathematics (where applicable) as preparation for the mathematical component of their degree, especially the applied mathematics strands. 
- The factors which motivated them to take Further Mathematics (if applicable).

- Their experiences of studying Further Mathematics (if applicable).

The questionnaire comprised a mixture of multiple choice, open and closed questions. It was developed by the researchers and an A-level Mathematics expert, and was open for responses during the first term of the academic year.

Analysis of quantitative data was conducted using SPSS, and qualitative data was coded using MAXQDA. Thematic analysis was used in order to analyse and describe participants' views of the qualification(s) and any suggestions they had for how the qualification(s) could have better suited the students' needs.

\section{DATA}

The number of responses to certain questions are reported throughout this section because not all questions were applicable to all participants, and not all participants answered all questions. Statistically significant differences are reported where they occurred - where $p$ values are not reported, the reader should assume that there were no statistically significant differences.

\section{A. Sample}

There were a total of 123 responses from students of Computer Science-related degrees. A further 31 questionnaire participants were students of joint honours in Mathematics and Computer Science (or similar). They have been excluded from analysis here as they will have had very different mathematical needs through their study of tertiary mathematics in their course. The views of some of these students are reported in [32].

A total of 24 universities were represented in the sample, with a median of 4 participants per university. The majority of participants studied in England (70.5\%), with 5.7\% in Scotland, 9.8\% in Northern Ireland and $13.8 \%$ in Wales. There were no statistically significant differences between the responses of students studying in different countries.

Table 1. Specific degrees studied by participants $(N=123)$

\begin{tabular}{|l|r|r|}
\hline \multicolumn{1}{|c|}{ Degree Title } & \multicolumn{1}{c|}{$\boldsymbol{N}$} & \multicolumn{1}{c|}{$\%$} \\
\hline Computer Science & 104 & 83.9 \\
\hline Computer Games Technology & 4 & 3.2 \\
\hline Computer Science and Artificial Intelligence & 2 & 1.6 \\
\hline Computing & 2 & 1.6 \\
\hline Computing and Information Technology & 2 & 1.6 \\
\hline Computing Science & 2 & 1.6 \\
\hline Computer Science and Business & 1 & 0.8 \\
\hline Computer Science and Electronics & 1 & 0.8 \\
\hline Computer Science and Games Technology & 1 & 0.8 \\
\hline Computer Science and Philosophy & 1 & 0.8 \\
\hline Computer Science and Visual Computing & 1 & 0.8 \\
\hline Computer Science, Business Management and & 1 & 0.8 \\
Accounting & & \\
\hline Computing Science and Physics & 1 & 0.8 \\
\hline
\end{tabular}

Students of both Bachelor's and Master's undergraduate degrees were represented in the sample, with $86.3 \%$ studying for the former. A total of 13 different specific degree titles were classified as 'Computer Science' (see Table 1), with 9.7\% of participants studying for joint honours with Computer Science.

Participants were asked whether they were required to have taken AS- or A-level Mathematics and/or Further Mathematics in order to be accepted onto their course of study. Most were required to have taken A-level Mathematics (see Table 2).

Table 2. Mathematical entry requirements $(N=123)$

\begin{tabular}{|l|r|r|}
\hline \multicolumn{1}{|c|}{ Mathematics Qualification(s) } & \multicolumn{1}{c|}{$\boldsymbol{N}$} & \multicolumn{1}{c|}{$\%$} \\
\hline AS-level Maths only & 2 & 1.6 \\
\hline A-level Maths only & 71 & 57.7 \\
\hline A-level Maths + AS-level Further Maths & 0 & 0.0 \\
\hline A-level Maths + A-level Further Maths & 6 & 4.9 \\
\hline No A-level Maths or Further Maths & 27 & 22.0 \\
\hline Unsure & 17 & 13.8 \\
\hline
\end{tabular}

Reflecting the dominance of male participation in undergraduate Computer Science [33], 83.9\% of students participating in this study were men.

\section{B. Participants' Academic Backgrounds}

Nearly half of the participants had studied A-level Mathematics only, with three taking only AS-level Mathematics. Of the 59 students who had taken Further Mathematics, $76.3 \%$ had taken the full A-level, and the remainder only AS Further Mathematics (see Table 3).

Table 3. AS- and A-level Mathematics qualifications held by participants $(N=123)$

\begin{tabular}{|l|r|r|}
\hline \multicolumn{1}{|c|}{ Mathematics Qualification(s) } & \multicolumn{1}{c|}{$\boldsymbol{N}$} & $\boldsymbol{\%}$ \\
\hline AS-level Maths only & 3 & 2.4 \\
\hline A-level Maths only & 61 & 49.6 \\
\hline A-level Maths + AS-level Further Maths & 14 & 11.4 \\
\hline A-level Maths + A-level Further Maths & 45 & 36.6 \\
\hline
\end{tabular}

The majority of participants achieved a grade A or A* in Mathematics (see Table 4), although this proportion was broadly in-line with the student body for such degree programmes. In 2011, 63.8\% of all Mathematics and Computer Science undergraduates ${ }^{4}$ achieved at least a grade A in A-level Mathematics [34]. Four participants $(3.2 \%)$ had taken Mathematics only to AS-level. All of them achieved a grade $\mathrm{A}$.

\footnotetext{
${ }^{4}$ National data is only available for Mathematics and Computer Science degree streams combined.
} 
Table 4. Students' A-level Mathematics and Further Mathematics grades

\begin{tabular}{|c|c|c|c|c|}
\hline \multirow[b]{3}{*}{ Grade } & \multicolumn{4}{|c|}{ \% Students } \\
\hline & \multicolumn{2}{|c|}{ Mathematics } & \multicolumn{2}{|c|}{ Further Mathematics } \\
\hline & 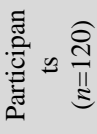 & 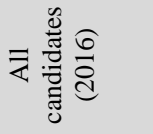 & 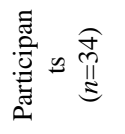 & 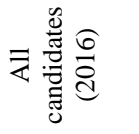 \\
\hline $\mathrm{A}^{*} / \mathrm{A}$ & 62.5 & 38.7 & 65.0 & 54.7 \\
\hline $\mathrm{B}$ & 29.2 & 19.7 & 10.0 & 18.1 \\
\hline $\mathrm{C}$ & 0.0 & 14.9 & 20.0 & 11.5 \\
\hline $\mathrm{D}$ & 2.5 & 10.5 & 5.0 & 7.1 \\
\hline $\mathrm{E}$ & 5.8 & 7.1 & 0.0 & 4.5 \\
\hline Fail & 0.0 & 9.7 & 0.0 & 4.1 \\
\hline
\end{tabular}

The participants of this study therefore give an overrepresentation of the higher-achieving end of A-level Mathematics and Further Mathematics performance.

\section{Optional A-level Mathematics Units Studied}

As the current structure of A-level Mathematics means that students are able to choose the applied mathematics units studied from several options (see Section I. B.), participants were asked to state which Further Pure Mathematics (FP1-4), Mechanics (M1-5), Statistics (S1-4) and Decision Mathematics (D1-2) units they had taken.

Statistics was the most frequently taken applied unit out of the three applied mathematics strands. Additionally, it was most common for participants who had studied Mechanics to have taken two units, and Further Pure Mathematics (only available to students who had taken AS- or A-level Further Mathematics) was mostcommonly studied to the third unit (see Fig. 1).

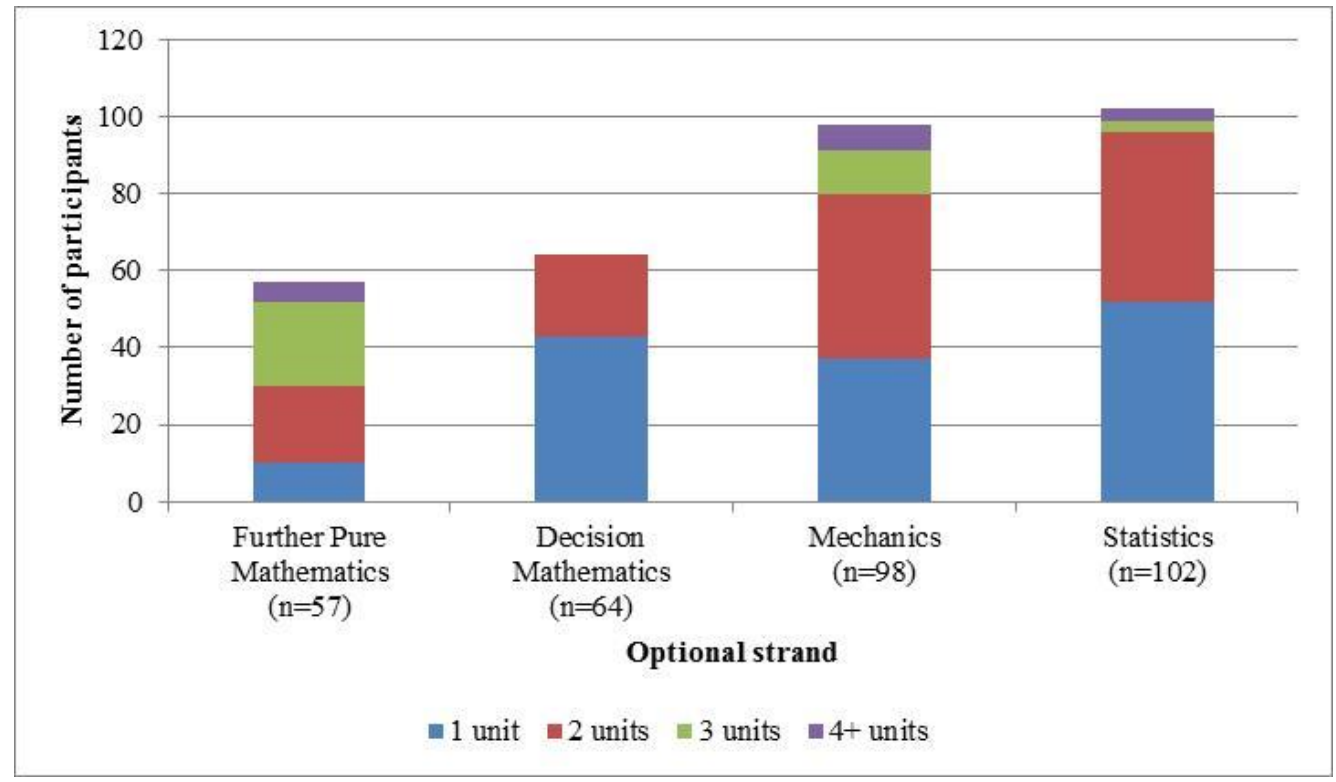

Fig.1. Number of optional units studied

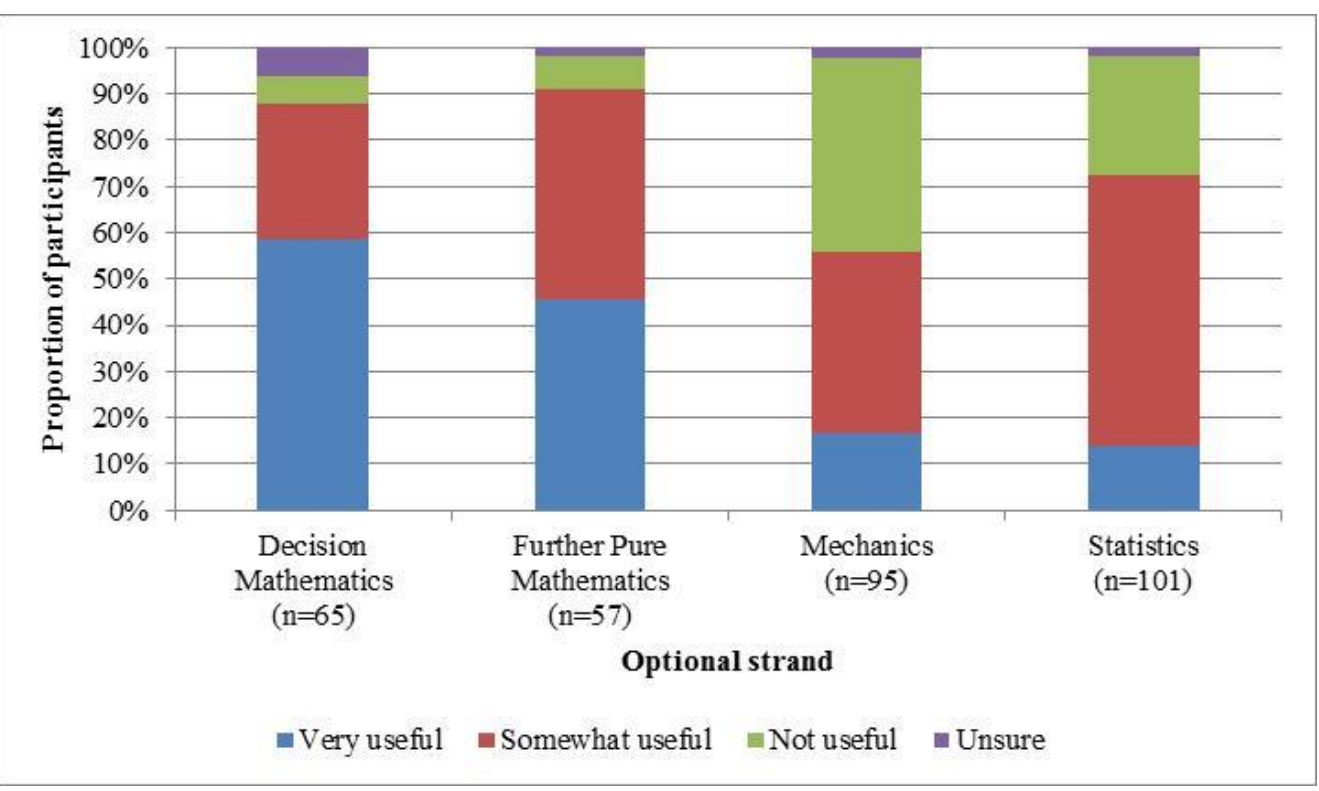

Fig.2. Students' views of the utility of optional units 


\section{Experiences of Optional A-level Units}

Although Decision Mathematics was studied by the fewest participants (see Fig. 1), Fig. 2 shows that these units were viewed most positively as preparation for undergraduate Computer Science. Whilst 58.5\% of participants who took Decision Mathematics described it as 'very useful', only $13.9 \%$ of participants who took Statistics, and $16.8 \%$ of participants who took Mechanics, echoed the same sentiments.

The strand described least favourably as preparation for Computer Science was Mechanics, with $42.1 \%$ of the participants who took it describing it as 'not useful'. There were gender differences in participants' responses here, however, with significantly more men describing it as 'very useful' than women (Fisher's exact test statistic $=10.105, p=.011$ ).

\section{E. Motivations for Studying Further Mathematics}

Of the participants who had studied Further Mathematics, the most influential factor on participants' decision to study it was their enjoyment of school mathematics (see Fig. 3).

Two other factors which notably influenced participants in their choice of Further Mathematics were:

- Prior success in school mathematics: $94.8 \%$ described coping well with GCSE Mathematics as influencing them to some extent, with $96.6 \%$ reporting the same of their perception that they were better at mathematics than at other subjects.

- Future plans: Nearly $70 \%$ of participants reported that 'thinking of doing a maths or maths-related degree at university' influenced them a lot in their decision to study Further Mathematics. This was particularly the case for the male participants, with a significantly greater proportion of them describing themselves as influenced 'a lot' than their female peers (Fisher's exact test statistic =
7.642, $p=.014)$. Additionally, $86.4 \%$ were influenced to some extent by a belief that they would need mathematics for their future career, and $89.8 \%$ by a perception that it would be a useful qualification to have.

The factor that influenced the fewest participants to study Further Mathematics was the influence of friends. Two other factors which had the least influence were:

- Encouragement by parents and teachers: Teacher and parental reinforcement only influenced $10.5 \%$ and $8.6 \%$ of participants, respectively, 'a lot'. However, significantly more women than men reported that they were influenced 'a little' by teacher reinforcement (Fisher's exact test statistic $=5.755, p=.046$ ).

- Prior success by the school mathematics department: Only $12.1 \%$ of participants reported that they were influenced 'a lot' in their decision by their schools' results.

\section{F. Experiences of Further Mathematics}

There were mixed responses from students regarding their experiences of Further Mathematics, although they were generally positive (see Table 5).

Encouragingly, no participant strongly disagreed with the statement 'I'm glad I did Further Maths', with $84.7 \%$ indicating agreement with it. A similar proportion reported that they enjoyed Further Mathematics. The subject appeared to have been difficult; most strongly agreed with the statement 'Further Maths was my most difficult A-level', and 84.4\% either strongly agreed or agreed that Further Mathematics was challenging. This comes despite so many of them achieving the top grades in it (see Fig. 2).

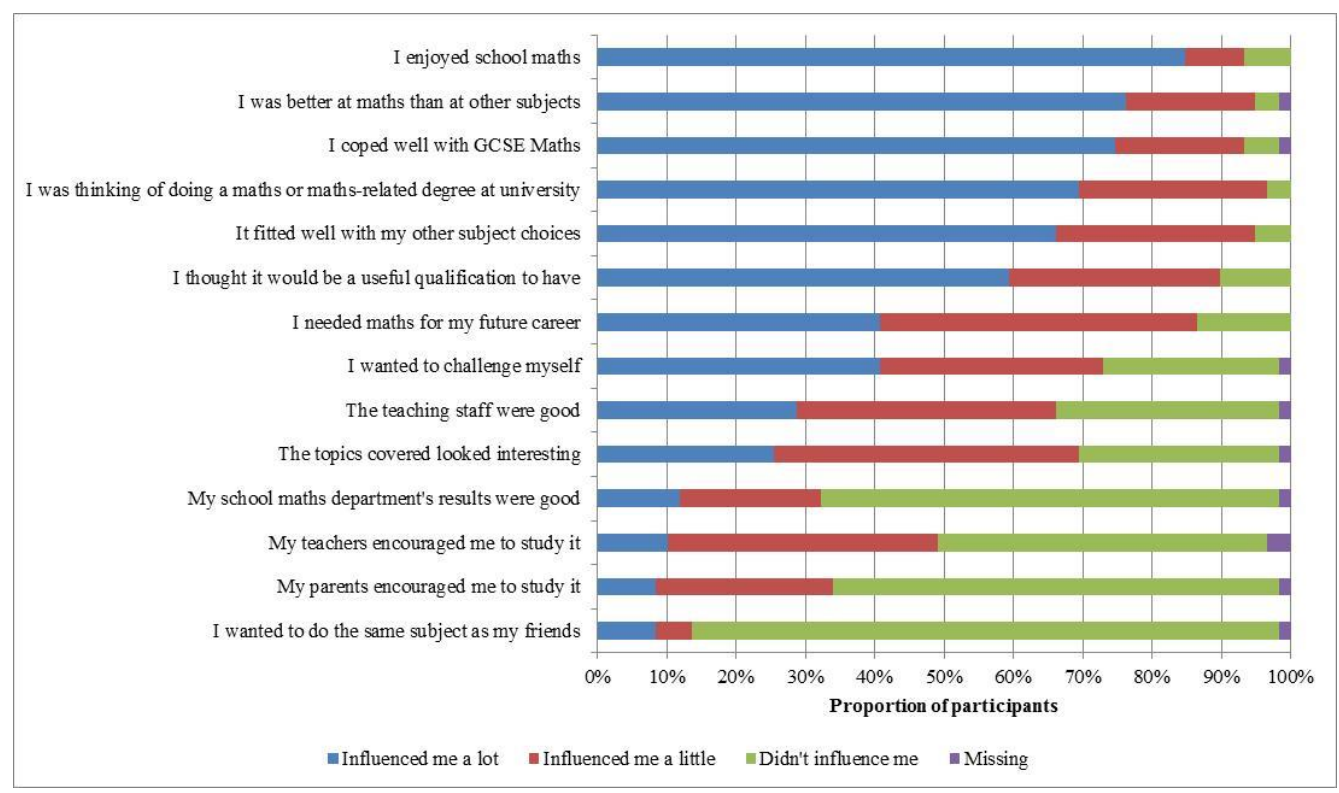

Fig.3. Computer Science undergraduates' motivations for studying Further Mathematics $(\mathrm{n}=59)$ 
Table 5. Participants' experiences of studying Further Mathematics

\begin{tabular}{|c|c|c|c|c|c|c|}
\hline & 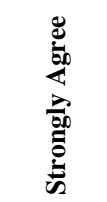 & 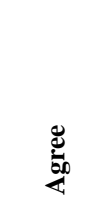 & 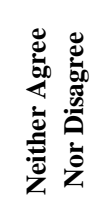 & 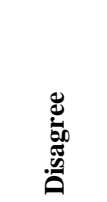 & 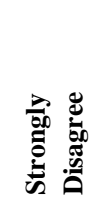 & 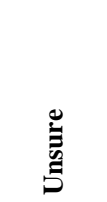 \\
\hline & \multicolumn{6}{|c|}{$\begin{array}{l}\text { Number of Participants } \\
(\%)\end{array}$} \\
\hline I'm glad I did Further Maths & $\begin{array}{l}36 \\
(61.0 \%)\end{array}$ & $\begin{array}{l}14 \\
(23.7 \%)\end{array}$ & $\begin{array}{l}7 \\
(11.9 \%)\end{array}$ & $\begin{array}{ll}2 \\
(3.4 \%)\end{array}$ & $\begin{array}{l}0 \\
(0.0 \%)\end{array}$ & $\begin{array}{l}0 \\
(0.0 \%)\end{array}$ \\
\hline I enjoyed Further Maths & $\begin{array}{l}25 \\
(42.4 \%)\end{array}$ & $\begin{array}{l}26 \\
(44.1 \%)\end{array}$ & $\begin{array}{ll}4 \\
(6.8 \%)\end{array}$ & $\begin{array}{ll}3 \\
(5.1 \%)\end{array}$ & $\begin{array}{l}1 \\
(1.7 \%)\end{array}$ & $\begin{array}{l}0 \\
(0.0 \%)\end{array}$ \\
\hline $\begin{array}{l}\text { In my first year at university, we were } \\
\text { taught material that I had learned in Further } \\
\text { Maths }\end{array}$ & $\begin{array}{l}25 \\
(42.4 \%)\end{array}$ & $\begin{array}{l}18 \\
(30.5 \%)\end{array}$ & $\begin{array}{ll}4 \\
(6.8 \%)\end{array}$ & $\begin{array}{l}7 \\
(11.9 \%)\end{array}$ & $\begin{array}{l}3 \\
(5.1 \%)\end{array}$ & $\begin{array}{ll}2 \\
(3.4 \%)\end{array}$ \\
\hline I found Further Maths challenging & $\begin{array}{l}23 \\
(39.0 \%)\end{array}$ & $\begin{array}{l}26 \\
(44.1 \%)\end{array}$ & $\begin{array}{l}7 \\
(11.9 \%)\end{array}$ & $\begin{array}{l}2 \\
(3.4 \%)\end{array}$ & $\begin{array}{l}0 \\
(0.0 \%)\end{array}$ & $\begin{array}{ll}1 \\
(1.7 \%)\end{array}$ \\
\hline $\begin{array}{l}\text { Further Maths was my most difficult A- } \\
\text { level }\end{array}$ & $\begin{array}{l}22 \\
(37.3 \%)\end{array}$ & $\begin{array}{l}10 \\
(16.9 \%)\end{array}$ & $\begin{array}{l}3 \\
(5.1 \%)\end{array}$ & $\begin{array}{l}15 \\
(25.4 \%)\end{array}$ & $\begin{array}{l}8 \\
(13.6 \%)\end{array}$ & $\begin{array}{l}1 \\
(1.7 \%)\end{array}$ \\
\hline $\begin{array}{l}\text { Studying A-level Maths and A/AS-level } \\
\text { Further Maths was sufficient preparation for } \\
\text { the mathematical component of my degree }\end{array}$ & $\begin{array}{l}21 \\
(35.6 \%)\end{array}$ & $\begin{array}{l}21 \\
(35.6 \%)\end{array}$ & $\begin{array}{l}6 \\
(10.2 \%)\end{array}$ & $\begin{array}{l}7 \\
(11.9 \%)\end{array}$ & $\begin{array}{l}4 \\
(6.8 \%)\end{array}$ & $\begin{array}{ll}0 \\
(0.0 \%)\end{array}$ \\
\hline $\begin{array}{l}\text { Most people on my university course } \\
\text { studied Further Maths }\end{array}$ & $\begin{array}{l}11 \\
(18.6 \%)\end{array}$ & $\begin{array}{l}8 \\
(13.6 \%)\end{array}$ & $\begin{array}{l}5 \\
(8.5 \%)\end{array}$ & $\begin{array}{l}17 \\
(28.8 \%)\end{array}$ & $\begin{array}{l}12 \\
(20.3 \%)\end{array}$ & $\begin{array}{l}6 \\
(10.2 \%)\end{array}$ \\
\hline
\end{tabular}

Table 6. Suggested topics for inclusion at A-level

\begin{tabular}{|c|c|c|c|c|c|c|}
\hline & \multirow[b]{2}{*}{ Topic } & \multicolumn{2}{|c|}{ Current A-level } & \multicolumn{2}{|c|}{ Reformed A-level } & \multirow{2}{*}{$\begin{array}{c}\text { A-level \& } \\
\text { GCSE } \\
\text { Computer } \\
\text { Science } \\
\text { (OCR) }\end{array}$} \\
\hline & & Maths & Further Maths & Maths & $\begin{array}{c}\text { Further } \\
\text { Maths }\end{array}$ & \\
\hline $\begin{array}{l}\text { Pure } \\
\text { Mathematics }\end{array}$ & $\begin{array}{l}\text { Proof } \\
\text { Logic } \\
\text { Boolean logic } \\
\text { Analysis }\end{array}$ & $\checkmark$ & $\checkmark$ & $\checkmark$ & $\checkmark$ & $\begin{array}{l}\checkmark \\
\checkmark \\
\checkmark\end{array}$ \\
\hline \multicolumn{2}{|l|}{ Set theory } & & optional & & optional & \\
\hline $\begin{array}{l}\text { Number } \\
\text { bases }\end{array}$ & $\begin{array}{l}\text { Binary } \\
\text { Denary } \\
\text { Hexadecimal } \\
\end{array}$ & & & & & $\begin{array}{l}\checkmark \\
\checkmark \\
\checkmark \\
\checkmark\end{array}$ \\
\hline \multicolumn{2}{|l|}{ Matrices } & & $\checkmark$ & & $\checkmark$ & \\
\hline \multicolumn{2}{|l|}{ Vectors } & $\checkmark$ & $\checkmark$ & $\checkmark$ & $\checkmark$ & \\
\hline \multicolumn{2}{|l|}{ Algorithms } & optional & optional & & optional & \\
\hline Calculus & $\begin{array}{l}\text { Partial derivatives } \\
\text { Limits in differentiation }\end{array}$ & & & & & \\
\hline $\begin{array}{l}\text { Probability } \\
\text { and statistics }\end{array}$ & $\begin{array}{l}\text { Combinatorics } \\
\text { Probability distributions }\end{array}$ & optional & optional & $\checkmark$ & optional & \\
\hline
\end{tabular}

Sources for A-level and GCSE content: [37, 38, 39, 40, 41, 42]

As would be expected given not all universities require prospective Computer Science undergraduates to have taken A-level Mathematics, the majority of participants disagreed that most of their peers had studied Further Mathematics. However, over three-quarters reported that there was an overlap between what they had been taught in Further Mathematics and the Mathematics that they had learnt in their first year at university. Together, the data which showed that $61.0 \%$ strongly agreed that they were glad that they took Further Mathematics, and that
$71.1 \%$ agreed that studying it alongside A-level Mathematics was sufficient preparation for the mathematical component of their degree, suggests that Further Mathematics is a worthwhile qualification for future Computer Science undergraduates to study.

G. Improvements to A-level Mathematics and Further Mathematics 
Participants were asked to respond to two openresponse questions, regarding additional topics that they would have found useful at A-level, and whether there were any improvements that they would like to see in either Mathematics or Further Mathematics.

There were 77 responses to the first question, regarding additional topics that would have been useful preparation at A-level. It was common for students who did not study D1 or D2 to state that they would have liked to study Decision Mathematics. Otherwise, the most frequently mentioned topics were number bases, proof, and set theory. These topics are summarised in Table 6.

The most commonly suggested improvement was making both A-levels more relevant to mathematics encountered in the study of Computer Science. These responses either suggested the introduction of examination questions that require more problem solving, or providing greater context and relevant examples for topics such as matrices and calculus, especially within examination questions. It was felt that the latter would have encouraged greater understanding of the material.

Participants made comments about the depth of A-level content. Most of these comments called for greater depth of the existing material, in order to better promote understanding and subsequently prepare students for the greater emphasis on logic and proof at university.
However, a slightly smaller proportion of students reported the opposite and indicated that, rather than greater depth, an increase in the variety of topics offered would be beneficial. This was usually with reference to a greater emphasis on topics considered to be relevant to the study of Computer Science, particularly more decision mathematics.

In terms of difficulty, there was no clear consensus. Broadly similar proportions of students reported that an increase in the difficulty of A-level would be welcome, to ease transition into university Mathematics, as they reported that the current level of difficulty was sufficient. Further comments indicated that a small minority of students (three) perceived units to be of different difficulty, particularly S1 and C1-2 which were considered to be too easy, and consequently these students suggested that there should be more consistency between units.

\section{H. A-level as Preparation for the Mathematical Component of Computer Science}

Participants were asked whether, as a whole, they believed that the A-level(s) had been useful preparation for the mathematical component of their degrees. Responses were encouraging (see Fig. 4).

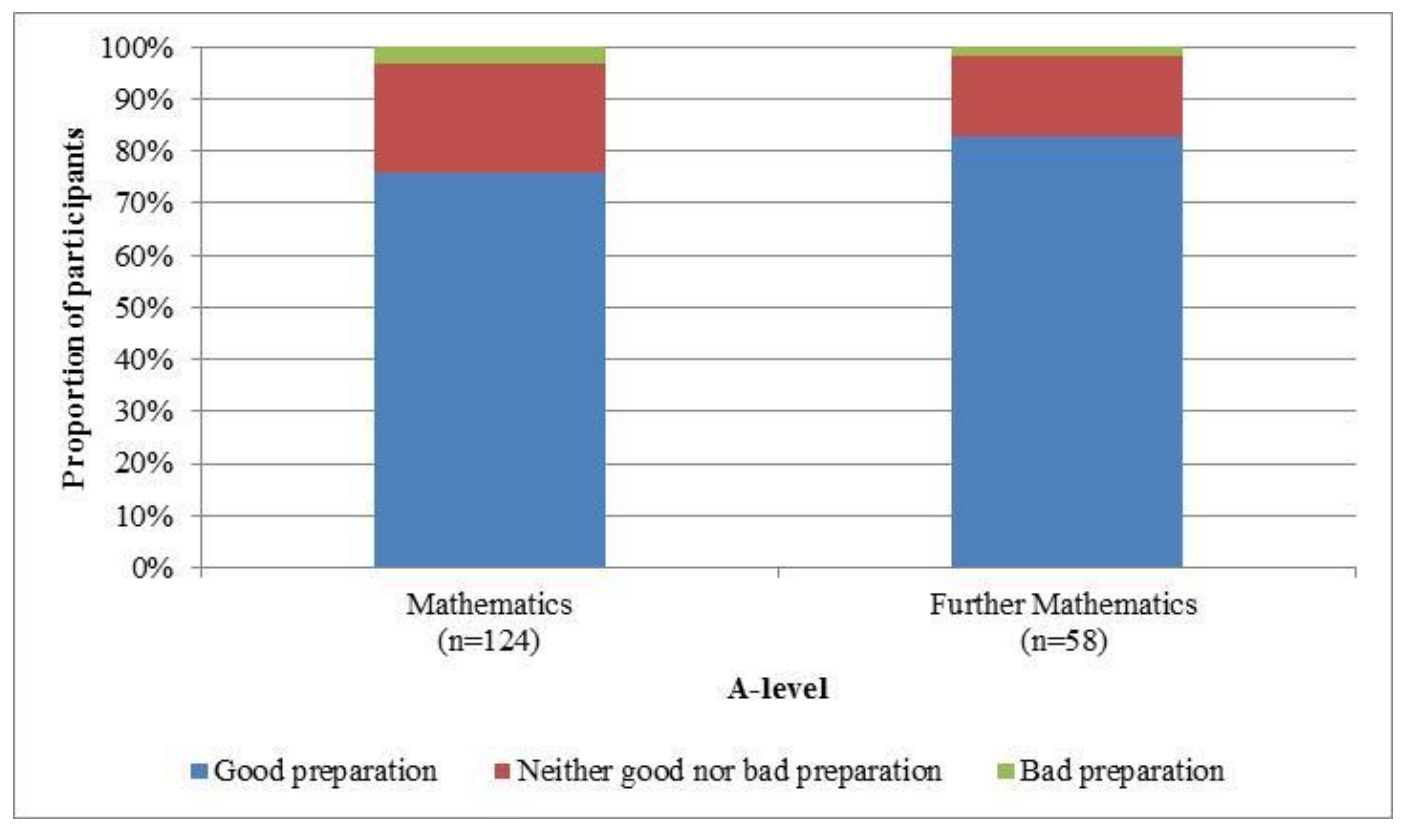

Fig.4. The A-levels as preparation for undergraduate Computer Science

Students' responses indicate that they valued these qualifications, with $75.8 \%$ of participants describing Alevel Mathematics as 'good preparation', and $82.8 \%$ reporting the same of Further Mathematics. This suggests that there are definite merits to studying Further Mathematics in addition to Mathematics, as only one participant described Further Mathematics as 'bad preparation' for their degree.

\section{LIMITATIONS}

Participation in this study was self-selecting in two ways. Not only did students self-select in choosing whether to fill in the questionnaire, but their universities also self-selected when choosing whether to disseminate details of the questionnaire to their students. Data reported in Section III has therefore been compared with national data in order to give an indication as to whether the sample was skewed in any way. 
As part of the self-selection, it is possible that students who felt particularly strongly about their mathematical preparedness and its impact on their transition to undergraduate study of Computer Science (positively or negatively) were more likely to take part.

This study only incorporated the views of students who had taken A-level Mathematics and/or Further Mathematics. It is not possible to contrast their experiences with those of students who did not study Alevel Mathematics and/or Further Mathematics, or who took alternative qualifications such as the International Baccalaureate, or who had their secondary education in other countries.

\section{CONCLUSION}

The data reported in this article indicates that Computer Science undergraduates consider both A-level Mathematics and Further Mathematics to be good preparation for the mathematical components of their course. In particular, students reported that Decision Mathematics units were the most useful applied units, and there was similar enthusiasm for Further Pure Mathematics units. These findings confirm that a good grounding in Mathematics is beneficial for Computer Science students. Consequently, it seems that prospective Computer Science undergraduates would benefit from taking at least A-level Mathematics.

Enjoyment and past performance in Mathematics were the main motivating factors in students' decision to take A-level Further Mathematics, with most reporting they had enjoyed the subject and were glad that they had taken it. Students' positivity was also reflected in more than three-quarters describing A-level Mathematics and Further Mathematics as 'good preparation' for the mathematical component of undergraduate Computer Science. Nonetheless it appears that there are a number of topic areas which students did not study which could have been helpful preparation. Most of these topics are available through the study of A-level Further Mathematics, with a substantial number taught as part of the reformed GCSE and A-level Computer Science.

Most high-ranking universities require prospective students to take A-level Mathematics if they are to be accepted onto a Computer Science course; however, lower-ranking universities typically only require students to have a 'good' pass in GCSE Mathematics in order to widen access. Further Mathematics is not currently a compulsory requirement by any university, though a handful of higher-ranking universities recommend its study. However, the forthcoming changes which will see decision mathematics topics only taught as part of ASand A-level Further Mathematics mean that the study of Further Mathematics will need to be actively encouraged amongst prospective undergraduate computer scientists if they are to be familiar with topics in this area before commencing university study.

Universities may be reluctant to require Further Mathematics for admission to their courses due to concerns about discouraging students and accessibility (not all schools are able to teach it for reasons often relating to staffing, student uptake and funding). However, they may wish to consider recommending it. Students were enthusiastic about their study of Further Mathematics, and many reported that they had chosen to study Further Mathematics because they were planning to study a Mathematics-related course at university. This indicates that students are aware that post-compulsory Mathematics is useful preparation for Computer Science despite universities typically not requiring applicants to have studied Further Mathematics. If universities recommend Further Mathematics as preparation for their course, without making it an explicit entry requirement, then this can only serve to better-prepare students for their future studies. In addition to acting as a gateway to the pre-university study of decision mathematics, the study of AS- or A-level Further Mathematics can expose students to other areas of Mathematics which are useful for the study of Computer Science, such as calculus, algebra and number theory.

Whilst the removal of Decision Mathematics options from A-level Mathematics could have significant implications for prospective students' preparation for university Computer Science, the reformed A-level Mathematics will still include content that has been found to be useful for Computer Science, and will therefore continue to be beneficial preparation. The introduction of prescribed content will also benefit university staff, as they will find fewer differences in the mathematical preparedness of their intake - although this will only be the case if they make an A-level Mathematics requirement.

Finally, despite the fact that A-level Computer Science is rarely an explicit entry requirement for degree-level Computer Science in the UK, Table 6 shows that there are helpful topics available through its study (or even through earlier study in the GCSE). Therefore, students should not dismiss the idea of studying it as its content is nonetheless relevant and would likely aid students in their preparation for university.

\section{CONCLUSION}

The data reported in this article confirms the need for universities to play close attention to the reform of Alevel Mathematics and Further Mathematics. Draft specifications for new A-level Further Mathematics qualifications all include Decision Mathematics options, demonstrating an awareness by awarding organisations that it is an important, appreciated and enjoyable topic which should be made available to students. It is now important that schools and universities keep prospective Computer Science students informed regarding the changes and give them appropriate advice and signposting so as to best-prepare them for the mathematical component of tertiary study. 


\section{ACKNOWLEDGEMENTS}

The authors wish to thank Karen Barden for proof reading this article.

\section{REFERENCES}

[1] Higher Education Statistics Agency. 2004. "Table 2e - All HE students by level of study, subject of study, domicile and gender 2002/03," [Online]. Available: https://www.hesa.ac.uk/dox/dataTables/studentsAndQuali fiers/download/subject0203.csv? $\mathrm{v}=1.0$ [Accessed $25 \mathrm{Jan}$ 2017].

[2] Higher Education Statistics Agency. 2016. "Students by subject of study, first year indicator, mode of study and level of study 2014/15," [Online]. Available: https://www.hesa.ac.uk/dox/dataTables/studentsAndQuali fiers/download/Subject1415.xlsx [Accessed 25 Jan 2017].

[3] Higher Education Statistics Agency. 2014. "Table SN3 Percentage of all UK domiciled entrants to full-time other undergraduate courses in 2011/12 who are no longer in HE in 2012/13," [Online]. Available: https://www.hesa.ac.uk/dox/performanceIndicators/1213_ J62I/sn3_1213.xlsx [Accessed 25 Jan 2017].

[4] Beaubouef, T. and Mason, J. 2005. "Why the high attrition rate for computer science students: Some thoughts \& observations", Inroads - The SIGCSE Bulletin, 37(2), 103-106.

[5] Joint Council for Qualifications. 2016. "A-level results," [Online]. Available:

http://www.jcq.org.uk/Download/examination-results/alevels/2016/a-as-and-aea-results [Accessed 25 Jan 2017].

[6] ALCAB. 2014. "Report of the alcab panel on mathematics \& further mathematics," [Online]. Available: https://alevelcontent.files.wordpress.com/2014/07/alcabreport-on-mathematics-and-further-mathematics-july2014.pdf [Accessed 25 Jan 2017].

[7] Hillman, J. 2014. Mathematics after 16: The state of play, challenges and ways ahead. London, Nuffield Foundation.

[8] Alexander, S., Clark, M., Loose, K., Amillo, J., Daniels, M., Boyle, R., Laxer, C., and Shinners-Kennedy, D. 2003. "Case studies in admissions to amd early performance in computer science degrees", ACM SIGCSE Bulletin conference, pp. 137-147.

[9] Gordon, N. 2004. "Mathematics and computing", MSOR Connections, 4(2), 10-13.

[10] Gregory, P. 2004. "Motivating computing students to learn mathematics", MSOR Connections, 4(3), 26-28.

[11] Porkess, R. 2013. A world full of data: Statistics opportunities across A-level subjects. London, Royal Statistical Society \& the Institute \& Faculty of Actuaries.

[12] OCR, 2015. "AS and A level computer science," [Online]. Available: http://www.ocr.org.uk/Images/171399-as-alevel-computer-science-summary-brochure.pdf [Accessed 25 Jan 2017].

[13] Boyle, R., Carter, J., and Clark, M. 2002. "What makes them succeed? Entry, progression and graduation in computer science", Journal of Further and Higher Education, 26(1), 3-18.

[14] Baldwin, D., Walker, H.M., and Henderson, P.B. 2013. "The roles of mathematics in computer science", $A C M$ Inroads, 4(4), 74-80.

[15] Quality Assurance Agency for Higher Education. 2007. Subject benchmark statement: Computing. Mansfield, QAA.
[16] Ofqual. 2014. GCE subject level conditions and requirements for computer science. Coventry, Ofqual.

[17] Nuffield Foundation. 2012. Mathematics in A-level assessments: A report on the mathematical content of $A$ level assessments in business studies, computing, economics, geography, psychology and sociology. London, Nuffield Foundation.

[18] Davenport, J.H., Wilson, D., Graham, I., Sankaran, G., Spence, A., Blake, J., and Kynaston, S. 2014. "Interdisciplinary teaching of computing to mathematics students: Programming and discrete mathematics", MSOR Connections, 14(1), 1-8.

[19] LTSN MathsTEAM. 2003. Diagnostic testing for mathematics. LTSN MathsTEAM Project.

[20] Manning, S., and Dix, A. 2008. "Identifying students' mathematical skills from a multiple-choice diagnostic test using an iterative technique to minimise false positives", Computers and Education, 51(3), 1154-1171.

[21] Cantwell Wilson, B. 2002. "A study of factors promoting success in computer science including gender differences", Computer Science Education, 12(1-2), 141-164.

[22] Katz, S., Allbritton, D., Aronis, J., Wilson, C., and Soffa, M.L. 2006. "Gender, achievement, \& persistence in an undergraduate computer science program", ACM SIGMIS Database, 37(4), 42-57.

[23] Katz, S., Aronis, J., Allbritton, D., Wilson, C., and Soffa, M.L. 2003. A study to identify predictors of achievement in an introductory computer science course. SIGMIS Conference, pp. 157-161.

[24] Bruce, K.B., Drysdale, R.L.S., Kelemen, C., and Tucker, A. 2003. "Why math?", Communications of the ACM, 46(9). 41-44.

[25] Gersting, J.L. 1990. "The other two rs in the discrete mathematics course", Computer Science Education, 1(4), 293-298.

[26] Ralston, A. 1981. "Computer science, mathematics, and the undergraduate curricula in both", The American Mathematical Monthly, 88(7), 472-485.

[27] Pioro, B.T. 2006. "Introductory computer programming: Gender, major, discrete mathematics, and calculus", Journal of Computing Sciences in Colleges, 21(5), 123129.

[28] Graham, R.L., Knuth, D.E., and Patashnik, O. 1994. Concrete mathematics: A foundation for computer science. Boston, Addison Wesley.

[29] Complete University Guide. 2016. "University subject tables 2016: Computer science" [Online]. Available: http://www.thecompleteuniversityguide.co.uk/leaguetables/rankings?s=Computer+Science [Accessed 25 Jan 2017].

[30] University of Cambridge Faculty of Mathematics. 2014. "Mathematics for the natural sciences workbook," [Online]. Available: http://www.maths.cam.ac.uk/undergrad/nstprospective/workbook.pdf [Accessed 25 Jan 2017].

[31] Darlington, D. and Bowyer, J. 2016. "The mathematics needs of higher education”, Mathematics Today, 52(1), 9.

[32] Darlington, E. 2015. Students' perceptions of A-level further mathematics as preparation for undergraduate mathematics. British Society for Research into Learning Mathematics, pp. 13-18.

[33] UCAS. 2015. "More women than men in two thirds of subject areas," [Online]. Available: https://www.ucas.com/sites/default/files/analysis_note_20 15_01.pdf [Accessed 25 Jan 2017]. 
[34] Vidal Rodeiro, C.L. 2012. Progression from A level mathematics to higher education. Cambridge, Cambridge Assessment.

[35] Department for Education. 2014. Further Mathematics GCE AS and A level subject content. London, Department for Education.

[36] Department for Education. 2014. Mathematics GCE AS and $A$ level subject content. London, Department for Education.

[37] Department for Education. 2016. Mathematics AS and A level content. London, Department for Education.

[38] Department for Education. 2016, Further mathematics AS and A level content. London, Department for Education.

[39] OCR. 2016. "A level specification: Computer science (H445)," [Online]. Available: http://www.ocr.org.uk/Images/170844-specificationaccredited-a-level-gce-computer-science-h446.pdf [Accessed 25 Jan 2017]

[40] OCR. 2016. "GCSE (9-1) specification: Computer science (J276)," [Online]. Available: http://www.ocr.org.uk/Images/170844-specificationaccredited-a-level-gce-computer-science-h446.pdf [Accessed 25 Jan 2017].
MSc in Educational Research Methodology from the University of Oxford, England. Her DPhil in Education from the University of Oxford concentrated on the transition between secondary and tertiary mathematics study relating to the role of assessment and students' approaches to learning. She serves on the editorial board of the Institute of Mathematics and its Applications' journal, Teaching Mathematics and its Applications.

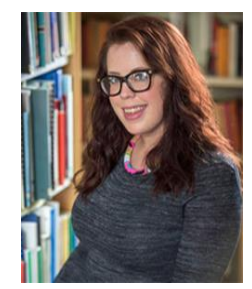

Jessica Bowyer has a BA in Politics, Psychology and Sociology from the University of Cambridge, England. She is currently studying for a MSc in Educational Research from the University of Exeter, England, and will begin work on a $\mathrm{PhD}$ in Education later this year. Her research concerns the differences in student attainment between different geographical areas. Prior to this she was a Research Assistant in the Assessment Research and Development Division at Cambridge Assessment.

\section{Authors' Profiles}

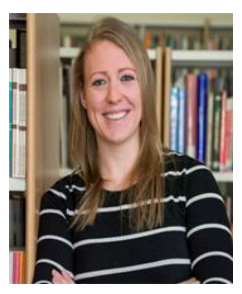

Ellie Darlington is a Research Officer in the Assessment Research and Development Division at Cambridge Assessment, a non-teaching, not-for-profit department of the University of Cambridge. She has a BSc in Mathematics and a MSc in Mathematics Education from the University of Warwick, England, and a

How to cite this paper: Ellie Darlington, Jessica Bowyer,"Decision Mathematics as Preparation for Undergraduate Computer Science", International Journal of Modern Education and Computer Science(IJMECS), Vol.9, No.4, pp.1-11, 2017.DOI: 10.5815/ijmecs.2017.04.01 